\title{
Pigmentos fotossintéticos em azevém suscetível e resistente ao herbicida glyphosate
}

\section{Photosynthetic pigments in Italian ryegrass susceptible and resistant to the herbicide glyphosate}

\author{
Tiago Edu Kaspary ${ }^{\mathrm{I}}$ Fabiane Pinto Lamego ${ }^{\text {II }}$ Sabrina Tolotti Peruzzo ${ }^{\mathrm{II}}$ \\ Isabel Bellinaso Pagliarini ${ }^{\mathrm{II}}$ Carlos Alberto Gonsiorkiewicz Rigon" ${ }^{\mathrm{II}}$
}

\section{RESUMO}

\begin{abstract}
O objetivo deste trabalho foi quantificar o teor de pigmentos fotossintéticos em biótipos de azevém (Lolium multiflorum) suscetíveis e resistentes ao glyphosate, por dois diferentes métodos, bem como, estabelecer uma correlação entre o indice de clorofila obtido pelo equipamento portátil e a metodologia clássica (clorofila extraível). Um experimento foi conduzido em casa de vegetação e laboratório da Universidade Federal de Santa Maria, Campus de Frederico Westphalen - RS em esquema fatorial $2 X 4$, em que o fator A equivaleu aos biótipos de azevém (resistente e suscetivel a glyphosate) e o fator $B$ a estádios de desenvolvimento das plantas (afilhamento, vegetativo I e II, e reprodutivo). O biótipo de azevém suscetível apresentou maiores teores de clorofila a, b, total e carotenoides, inferindo em um maior potencial competitivo frente ao biótipo resistente ao herbicida. A determinação do teor de clorofila pelo determinador portátil apresentou alta correlação com o método clássico de determinação de pigmentos fotossintéticos, podendo, assim, ser usado com precisão na avaliação deste, proporcionando economia de tempo bem como do uso de reagentes.
\end{abstract}

Palavras-chave: Lolium multiflorum, clorofilas, carotenoides, clorofilômetro.

\section{ABSTRACT}

The aim of this study was to quantify the content of photosynthetic pigments in ryegrass (Lolium multiflorum) susceptible and resistant to glyphosate, by two different methods, as well as the correlation between chlorophyll content obtained by portable and classical methodology (chlorophyll extractable). An experiment was conducted in a greenhouse and laboratory of the Federal University of Santa Maria, Frederico Westphalen Campus - RS in a $2 X 4$ factorial scheme, where factor A was equivalent to ryegrass (resistant and susceptible to glyphosate) and factor $B$ to the developmental stages of plant (tillering, vegetative I and II and reproductive stage). The susceptible ryegrass biotype showed higher contents of chlorophyll $a, b$, and total carotenoids, inferring a superior competitive potential to the herbicide-resistant biotype. The determination of chlorophyll by portable determinato showed high correlation with the classical method of determination of photosynthetic pigments, and can thus be used to assess this accurately, saving time, as well as the use of reagents.

Key words: Lolium multiflorum, chlorophyll, carotenoids, chlorophyll meter.

\section{INTRODUÇÃO}

O azevém (Lolium multiflorum L.) é uma gramínea anual de inverno, pertencente à família Poaceae, com ampla utilização como forrageira e cobertura de solo para os sistemas conservacionistas, como o sistema de semeadura direta. Contudo, pela adaptabilidade a solos de baixa e média fertilidade e por ser de fácil dispersão, o azevém está presente e caracteriza-se como planta daninha em praticamente todas as lavouras de inverno/primavera da região Sul do Brasil, principalmente aquelas de trigo, cevada, aveia e milho.

O controle do azevém se baseava quase que exclusivamente pelo uso do herbicida glyphosate. No entanto, o surgimento de biótipos resistentes a esse herbicida tornou seu controle ainda mais difícil e oneroso. A resistência a herbicidas pode acarretar

\footnotetext{
IPrograma de Pós-graduação em Fitotecnia, Universidade Federal do Rio Grande do Sul (UFRGS), Av. Bento Gonçalves, 7712, 91540-000, Porto Alegre, RS, Brasil. E-mail: tiago_kaspary@yahoo.com.br. Autor para correspondência.

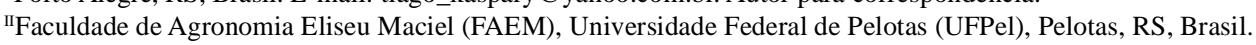

III Universidade Federal de Santa Maria (UFSM), campus de Frederico Westphalen, Frederico Westphalen, RS, Brasil. Recebido 01.09.13 Aprovado 14.04.14 Devolvido pelo autor 02.08.14 CR-2013-1177.R2
} 
mudanças biológicas nos biótipos resistentes, as quais podem ser favoráveis ou não a sua adaptabilidade ecológica e capacidade competitiva. Nesse contexto, FERREIRA et al. (2006) evidenciaram a redução na capacidade competitiva de biótipo de azevém resistente a glyphosate quando da ausência da aplicação do herbicida, inferindo em maior potencial competitivo dos indivíduos suscetíveis. Embora o mecanismo de resistência no biótipo resistente não tenha sido determinado e o alvo do herbicida glyphosate não esteja diretamente relacionado à produção dos pigmentos fotossintéticos, a evolução da resistência em plantas daninhas pode causar penalidades que, consequentemente, poderão afetar a competitividade dessas. GALVAN et al. (2012) observaram menor quantidade de floema em relação ao xilema em folhas de azevém resistentes a glyphosate, o que pode colaborar para uma menor sensibilidade ao herbicida.

A competitividade está relacionada à utilização eficiente dos recursos do meio no qual a planta se encontra, sendo a radiação solar (luz) um importante componente no estabelecimento desta relação (RIZZARDI et al., 2001). As clorofilas e os carotenoides são os principais pigmentos ligados à eficiência fotossintética e, com o estabelecimento das relações de competitividade que a espécie manifesta no crescimento e adaptação aos diversos ambientes (FORCE et al., 2003). Ainda, FLECK et al. (2003) afirmam que a maior taxa de acúmulo líquido e elevada velocidade de crescimento em plantas estão relacionados a elevados teores de pigmentos nas folhas.

Os pigmentos fotossintéticos são determinados na maioria dos casos por metodologia clássica, que consiste na coleta destrutiva da folha do vegetal, além de compreender uma prática onerosa por envolver o uso de reagentes em laboratório. Diferentemente, os leitores portáteis de clorofila utilizam princípios não destrutivos, simples e instantâneos, possibilitando estudos ontogênicos foliares das culturas (SALLA et al., 2007). Clorofilômetros portáteis estão sendo utilizados com êxito na determinação de pigmentos fotossintéticos em diferentes espécies, como relatado por CIGANDA et al. (2009), em milho, e RIGON et al. (2013), na cultura do pinhão-manso.

A partir da hipótese de que biótipos de azevém resistentes ao glyphosate apresentam capacidade fotossintética inferior em função de menor teor de clorofilas e carotenoides, pode-se inferir que eles poderão ser menos competitivos quando em convívio com aqueles suscetíveis na ausência do herbicida. Dessa forma, a avaliação das características competitivas de uma população de plantas daninhas poderá favorecer a antecipação na tomada de decisão dessa espécie, podendo-se promover a competição dos biótipos e minimizar o avanço da resistência. O objetivo deste trabalho é quantificar e comparar teores de pigmentos fotossintéticos em biótipos de Lolium multiflorum suscetíveis e resistentes ao herbicida glyphosate, através de dois diferentes métodos: clorofila extraível e leitura do clorofilômetro, bem como avaliar a existência de correlação significativa entre os métodos.

\section{MATERIAL E MÉTODOS}

O presente trabalho foi conduzido em casa de vegetação e no Laboratório de Análises Químicas do Departamento de Ciências Agronômicas e Ambientais da Universidade Federal de Santa Maria (UFSM), Campus de Frederico Westphalen-RS, no período de junho a outubro de 2012. Sementes de azevém, biótipo $\mathrm{S}$ (Suscetível) e biótipo $\mathrm{R}$ (Resistente), originários de lavouras comerciais situadas no município de Novo Barreiro - RS, previamente confirmadas como S e R (KASPARY et al., 2010), foram semeadas em vasos plásticos com volume de $6 \mathrm{~L}$, preenchidos com substrato agrícola (TecnoMax) e, após a emergência, apenas uma planta foi mantida por vaso.

$\mathrm{O}$ delineamento experimental utilizado foi inteiramente casualizado, arranjado em esquema fatorial $2 \times 4$, sendo o fator A correspondente aos biótipos de azevém: Suscetível e Resistente ao herbicida glyphosate; e o fator B a quatro estádios de desenvolvimento das plantas: estádio de afilhamento (28 dias após a semeadura (DAS)), estádio vegetativo I (42 DAS), vegetativo II (57 DAS) e estádio reprodutivo (92 DAS).

Para as avaliações dos teores de pigmentos fotossintéticos, em cada estádio de desenvolvimento, duas folhas do terço médio de quatro plantas de cada biótipo eram analisadas e, posteriormente, coletadas, totalizando oito repetições por tratamento. $\mathrm{O}$ teor relativo de clorofila foi aferido individualmente pelo método do medidor portátil ClorofiLOG1030 ${ }^{\circledR}$, no qual a leitura do índice foi realizada diretamente sobre a folha, sem estas serem retiradas da planta. Em seguida, as mesmas folhas foram coletadas e então levadas ao laboratório para as análises pelo método extraível, segundo a metodologia proposta por HISCOX \& ISRAELSTAM (1979).

Para a dissolução das amostras, 0,05g de massa fresca de folhas foram colocadas em tubos 
de ensaio onde foram adicionados $3 \mathrm{ml}$ do reagente dimetilsulfóxido (DMSO), com incubação a $65^{\circ} \mathrm{C}$ por 45min, em banho-maria. Na sequência, procedeu-se à agitação manual, acrescentado mais $2 \mathrm{ml}$ de DMSO, por 30 segundos. Em seguida, 2,5ml da solução final contendo os pigmentos foi lida em espectrofotômetro Biomate $^{\circledR \mathrm{tm} 3}$, por meio dos comprimentos de onda de 470,645 e $663 \mathrm{~nm}$, para carotenoides, clorofila " $b$ " e clorofila " $a$ ", respectivamente. Os valores obtidos em cada comprimento de onda foram utilizados nas equações relatadas por LICHTENTHALER (1987), tendo por base a massa fresca (MF) na determinação dos teores de clorofila $a, b$, total e de carotenoides, expressos em $\mathrm{mg} \mathrm{g}^{-1}$.

Os dados obtidos para cada método foram submetidos à análise de variância, através do teste $\mathrm{F}$, e as médias dos tratamentos comparadas aplicando-se o teste de Tukey, com nível de 5\% de probabilidade. Também se realizaram análises de correlação entre o método extraível e a leitura do clorofilômetro. Os ajustes das curvas foram realizados pelas funções linear e quadrática, conforme coeficiente de determinação, por meio do programa Sigmaplot ${ }^{\circledR}$ 11.2.

\section{RESULTADOS E DISCUSSÃO}

Os resultados obtidos através da leitura pelo clorofilômetro demonstraram significância estatística para a interação dos fatores biótipos e estádios $(\mathrm{P} \leq 0,05)$ (Tabela 1). Na comparação entre biótipos, constatou-se maior índice relativo de clorofila no biótipo $\mathrm{S}$ em todos os estádios de avaliação, em comparação ao biótipo R. Maiores teores de pigmentos fotossintéticos podem proporcionar, ao determinado biótipo, um melhor aproveitamento da luminosidade do meio e maior taxa de acúmulo líquida de fotoassimilados, atrelado também à elevada velocidade de crescimento (FLECK et al., 2003).

$\mathrm{Na}$ comparação dos índices de clorofila entre os estádios de desenvolvimento dos biótipos, o biótipo $\mathrm{S}$ apresentou valores superiores nos estádios vegetativos I e II, equivalentes a 48,81 e 48,83, respectivamente (Tabela 1). Dessa forma, é observado um acréscimo significativo no índice de clorofila, a partir do valor obtido no estádio de afilhamento, 40,73. Contudo, o índice decresce significativamente quando do estádio reprodutivo, 41,54, não diferindo do valor observado no primeiro estádio de avaliação. $\mathrm{O}$ mesmo foi observado para o biótipo $\mathrm{R}$, onde apresentou índice estatisticamente inferior no estádio de afilhamento, 35,01 e valores elevados nos estádios vegetativos I e II, 43,75 e 44,85, respectivamente. Porém, no estádio reprodutivo, o índice voltou a ser inferior, 34,51, não diferindo do estádio inicial. Desse modo, observa-se um comportamento similar entre as épocas de avaliação, para cada biótipo isoladamente.

SCHUELTER et al. (2003), ao trabalharem com diferentes cultivares de tomateiro, encontraram comportamento diferencial e redução do teor de clorofila e de carotenoides 60 dias após implantação das mudas, gerando senescência precoce de folhas. MOURA (2004), em estudo também com tomates, afirmou que frutos menores foram gerados pela redução da taxa fotossintética, em função da queda precoce dos teores de clorofila pelas folhas. Para os biótipos de azevém, a redução precoce dos teores de clorofila poderá gerar menor número de sementes viáveis e/ou menos vigorosas.

$\mathrm{Na}$ avaliação dos pigmentos fotossintéticos em Lolium multiflorum, realizada pela metodologia clássica ou de clorofila extraível, novamente constatou-se interação significativa para os fatores avaliados $(\mathrm{P} \leq 0,05)$ (Tabela 1$)$. Em todas as variáveis avaliadas, teor de clorofila $a$, teor de clorofila $b$, teor de clorofila total e carotenoides, o biótipo S apresenta valores superiores ao R. Os dados observados pelo método do clorofilômetro estão em conformidade ao obtido pelo método clássico. Todavia, a partir do método de clorofila extraível, foram determinados os teores de clorofila $a, b$, total e carotenoides (mg $\mathrm{g}^{-1} \mathrm{mf}$ ), sendo que para todas as variáveis o biótipo $\mathrm{S}$ apresentou valores superiores.

$\mathrm{Na}$ comparação de estádios pela metodologia clássica, o biótipo $\mathrm{S}$, assim como observado para o índice de clorofila, apresentou incremento significativo para as clorofilas $a$, clorofila $b$, clorofila total e carotenoides (Tabela 1) até o estádio vegetativo II, seguido de redução no estádio reprodutivo. $\mathrm{O}$ mesmo comportamento foi apresentado pelo biótipo $\mathrm{R}$, com acréscimo de forma progressiva do estádio de afilhamento até o vegetativo II, com redução no estádio reprodutivo, para todas as variáveis analisadas.

Os resultados obtidos pelas duas diferentes metodologias, clorofilômetro e laboratório, ao serem correlacionados, apresentam alta relação entre as leituras, apresentando coeficientes de determinação de 0,96 para a clorofila $a$, para ambos os biótipos, $\mathrm{S}$ e $\mathrm{R}$, conforme as figuras $1 \mathrm{~A}$ e $1 \mathrm{~B}$, respectivamente. Sendo assim, é possível estimar de forma confiável, a partir dos modelos matemáticos obtidos nas figuras $1 \mathrm{~A}$ e 1B, os teores de clorofila $a$ em Lolium multiflorum, uma vez que as leituras obtidas pelo aparelho portátil se mostraram precisas, corroborando o observado para as culturas do milho e pinhão-manso, que apresentaram alta correlação entre as leituras do 
Tabela 1 - Índice relativo de clorofila por ClorofiLOG e clorofila a, clorofila $b$, clorofila total e carotenoides ( $\mathrm{mg} \mathrm{g}^{-1} \mathrm{mf}$ ), de acordo com método extraível, em biótipo de Lolium multiflorum, suscetível e resistente ao herbicida glyphosate.

\begin{tabular}{|c|c|c|c|c|}
\hline Biótipo & Afilhamento & Vegetativo-I & Vegetativo-II & Reprodutivo \\
\hline Suscetível & $a^{2} 40,73 B$ & a $48,81 \mathrm{~A}$ & a $48,83 \mathrm{~A}$ & a $41,54 \mathrm{~B}$ \\
\hline Resistente & b $35,01 \mathrm{~B}$ & b $43,75 \mathrm{~A}$ & b $44,85 \mathrm{~A}$ & b $34,51 \mathrm{~B}$ \\
\hline Média & 37,87 & 46,28 & 46,84 & 38,02 \\
\hline $\mathrm{CV}^{1}(\%)$ & \multicolumn{4}{|c|}{5,15} \\
\hline $\mathrm{S}$ & a $1,3092 \mathrm{~B}$ & a $1,8261 \mathrm{~A}$ & a $1,8686 \mathrm{~A}$ & a $1,3685 \mathrm{~B}$ \\
\hline $\mathrm{R}$ & b $1,0481 \mathrm{~B}$ & b $1,5982 \mathrm{~A}$ & b $1,6104 \mathrm{~A}$ & b $1,1601 \mathrm{~B}$ \\
\hline Média & 1,1786 & 1,7121 & 1,7395 & 1,2643 \\
\hline $\mathrm{CV}(\%)$ & \multicolumn{4}{|c|}{2,55} \\
\hline $\mathrm{S}$ & a 0,4118 B & a $0,5792 \mathrm{~A}$ & a $0,5159 \mathrm{~A}$ & a 0,3959 B \\
\hline $\mathrm{R}$ & b 0,2975 B & b $0,4821 \mathrm{~A}$ & b $0,4435 \mathrm{~A}$ & b $0,3160 \mathrm{~B}$ \\
\hline Média & 0,3546 & 0,5306 & 0,4797 & 0,3559 \\
\hline C.V. ${ }^{1}(\%)$ & \multicolumn{4}{|c|}{10,09} \\
\hline $\mathrm{S}$ & a $1,7210 \mathrm{~B}$ & a $2,4053 \mathrm{~A}$ & a $2,3845 \mathrm{~A}$ & a $1,7644 \mathrm{~B}$ \\
\hline $\mathrm{R}$ & b $1,3456 \mathrm{~B}$ & b 2,0803 A & b 2,0539A & b $1,4761 \mathrm{~B}$ \\
\hline Média & 1,5333 & 2,2428 & 2,2192 & 1,6202 \\
\hline CV (\%) & \multicolumn{4}{|c|}{2,44} \\
\hline $\mathrm{S}$ & a $0,5747 \mathrm{~B}$ & a 0,6613 A & a $0,6479 \mathrm{~A}$ & a $0,5507 \mathrm{~B}$ \\
\hline $\mathrm{R}$ & b $0,4088 \mathrm{~B}$ & b $0,5203 \mathrm{~A}$ & b $0,4935 \mathrm{~A}$ & b $0,4139 \mathrm{~B}$ \\
\hline Média & 0,4917 & 0,5908 & 0,5707 & 0,4823 \\
\hline C.V. ${ }^{1}(\%)$ & \multicolumn{4}{|c|}{7,34} \\
\hline
\end{tabular}

${ }^{1}$ Coeficiente de Variação.

${ }^{2}$ Letras maiúsculas semelhantes na linha e letras minúsculas na coluna, não diferem entre si pelo teste de DMS a 5\% de significância.

clorofilômetro e da clorofila $a$ extraída em laboratório (CIGANDA et al., 2009; RIGON et al., 2013).

Para a clorofila $b$, as correlações realizadas entre o índice observado pelo aparelho e o mensurado em laboratório novamente apresentaram elevados coeficientes de determinação para o biótipo S e R de Lolium multiflorum, 0,92 e 0,94, respectivamente (Figura 1C e 1D). Contudo, NEVES et al. (2005) salientam que a leitura da clorofila $b$ através de aparelhos portáteis é mais difícil que a mensuração da clorofila $a$. Isto está relacionado ao comprimento de onda emitido pelo aparelho aproximar-se mais ao pico de absorção da clorofila $a$, que é de $660 \mathrm{~nm}$, enquanto que a absorção do pigmento " $b$ " apresenta dois picos, o primeiro próximo a 500 e outro a 650nm (DI VITTORIO, 2009). Entretanto, neste estudo, verificou-se alta eficiência nas leituras do clorofilômetro em relação às análises laboratoriais para a espécie $\boldsymbol{L}$. multiflorum, com coeficiente de determinação de 0,90 .

Quando correlacionados, os valores observados pelos dois métodos para a clorofila total foram observados elevados coeficientes de determinação $(0,96)$ para ambos os biótipos, S e R. Novamente, é possível, a partir do observado, proceder o ajuste a um modelo matemático de alta confiabilidade para essa variável, quando da análise de biótipos de azevém suscetível e resistente ao glyphosate (Figura 1E e 1F). CIGANDA et al. (2009) e RIGON et al. (2013) também observaram elevados coeficientes de correlação entre os métodos de determinação de clorofila total para o milho e pinhãomanso, respectivamente.

As figuras 2A e 2B apresentam a correlação do índice observado pelo clorofilômetro e o teor de carotenoides em folhas de Lolium multiflorum, sendo que os coeficientes de determinação apresentados são 0,93 para o biótipo $\mathrm{S}$ e 0,91 para o biótipo R. Ressalta-se que a determinação do teor de carotenoides é importante, uma vez que estes atuam como fotoprotetores no fotossistema II, dissipando o excesso energético incidente sobre a folha na forma de luz, evitando por meio de seu 

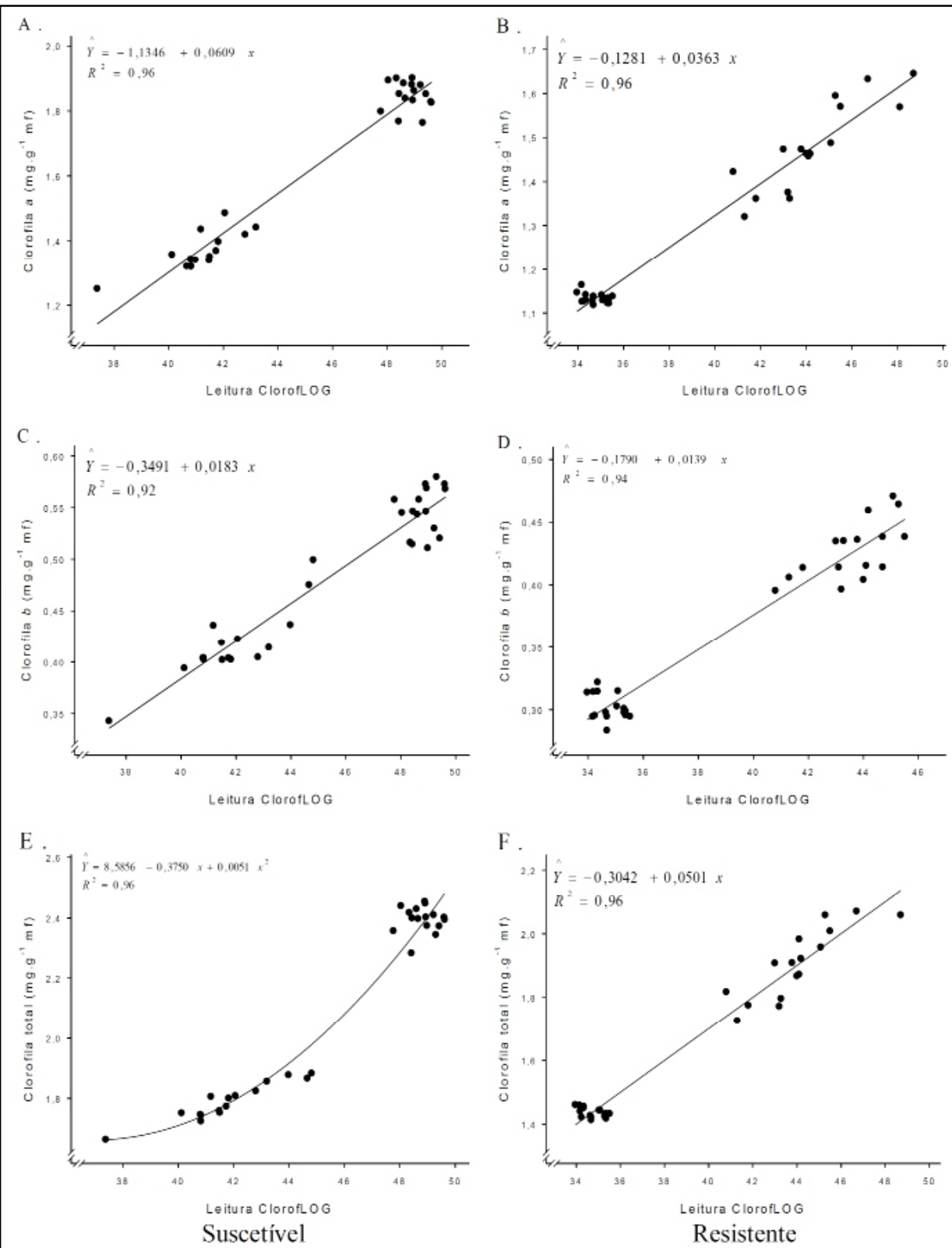

Figura 1 - Relação entre leitura do clorofilômetro portátil ClorofiLOG ${ }^{\circledR}$ e teores de clorofila $a$ (A- suscetível e B-resistente), clorofila $b$ (C-suscetível e D- resistente), clorofila total (E- suscetível e Fresistente), em Lolium multiflorum.

elevado potencial antioxidante, que as clorofilas sejam danificadas (LI et al., 2010). Já nas figuras 2C e $2 \mathrm{D}$, estão descritas as relações entre a clorofila $a$ pela clorofila $b$, determinadas em laboratório, com o índice de clorofila obtido com o clorofilômetro, sendo que as correlações entre os valores apresentaram o coeficiente de determinação de 0,86 para o biótipo $\mathrm{S}$ e 0,88 para o biótipo R. Esta relação, por sua vez, expressa a capacidade da planta em captar luz sob condições de sombreamento, conforme relatado por NAKAZONO et al. (2001). Os resultados, estão de acordo com o observados por RIGON et al. (2013) que, ao utilizarem o determinador portátil ClorofiLOG para a cultura do pinhão-manso, obtiveram coeficiente de determinação de 0,73 .

Em trabalho prévio, realizado com os mesmos biótipos de azevém, KASPARY et al. (2012) constataram menor acúmulo de massa 

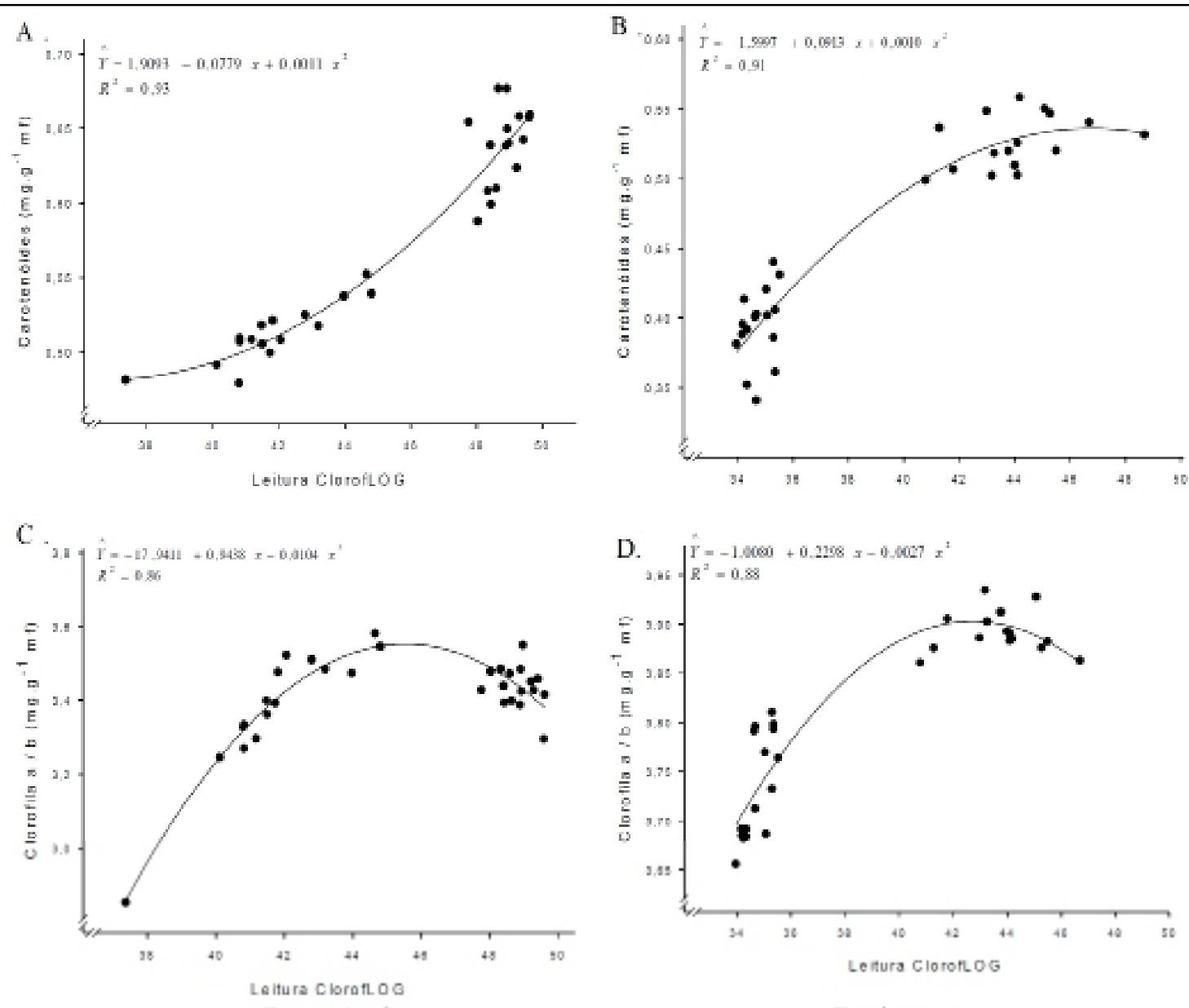

Suscetivel

\section{Resistente}

Figura 2 - Relação entre leitura do clorofilômetro portátil ClorofiLOG ${ }^{\circledR}$ e teores de carotenoides (A- suscetível e B- resistente) e clorofila a/b (C-suscetível e D- resistente), em Lolium multiflorum.

seca total, assim como menor estatura de planta para o biótipo resistente; contudo, estudos mais detalhados estão sendo conduzidos, uma vez que a produção de sementes pelo biótipo resistente foi superior, quando comparada ao biótipos $\mathrm{S}$ de azevém. A eficiência fotossintética e o acúmulo de fotoassimilados, assim como o crescimento, estão associados diretamente aos teores de clorofila foliar (SOUSA et al. 2010). Nesse sentido, a partir dos inferiores índices de clorofila observados para o biótipo R, é possível inferir sob sua menor capacidade competitiva frente ao biótipo S. Dessa forma, uma vez que ambos os biótipos ocorram na ausência do herbicida glyphosate em nível de campo, é possível que haja supressão do biótipo $\mathrm{R}$ de L. multiflorum pelo biótipo $\mathrm{S}$, podendo se tornar uma estratégia para o manejo da resistência nessa espécie.

\section{CONCLUSÃO}

A determinação de pigmentos fotossintéticos através do uso de clorofilômetro portátil com modelos matemáticos ajustados é precisa e proporciona economia de tempo e reagentes, quando comparada ao método de clorofila extraível. Biótipo de Lolium multiflorum resistente ao herbicida glyphosate apresenta diferença em teor de pigmentos fotossintéticos quando comparado ao suscetível, sendo requeridos estudos mais detalhados para determinar se este resultado infere em menor capacidade competitiva pelo biótipo.

Ciência Rural, v.44, n.11, nov, 2014. 


\section{REFERÊNCIAS}

CIGANDA, V. et al. Non-destructive determination of maize leaf and canopy chlorophyll content. Journal of Plant Physiology, v.166, p.157-167, 2009. Disponível em: <http://www.sciencedirect. com/science/article/pii/S017616170800103X>. Acesso em: 08 ago. 2013. doi: 10.1016/j.jplph.2008.03.004.

DI VITTORIO, A.V. Enhancing a leaf radiative transfer model to estimate concentrations and in-vivo specific absorption coefficients of total carotenoids and chlorophylls a and b from single-needle reflectance and transmittance. Remote Sens. Environ, v.113, p.1948-1966, 2009. Disponível em: <http://www.deepdyve.com/ lp/elsevier/enhancing-a-leaf-radiative-transfer-model-to-estimateconcentrations-apmgq3zosw>. Acesso em: 08 ago. 2013. doi: 10.1016/j.rse.2009.05.002.

FERREIRA, E.A. et al. Glyphosate no controle de biótipos de azevém e impacto na microbiota do solo. Planta Daninha, v.24, n.3, p.573-578, 2006. Disponível em: <http://www.scielo.br/scielo. php?script=sci_arttext\&pid=S0100-83582006000300021 >. Acesso em: 08 ago. 2013. doi: 10.1590/S0100-83582006000300021.

FLECK, N.G. et al. Velocidade de estabelecimento em cultivares de arroz irrigado como característica para aumentar a habilidade competitiva com plantas concorrentes. Ciência Rural, v.33, n.4, p.635-640, 2003. Disponível em: <http://www.scielo.br/scielo.php? script=sci_arttext\&pid=S0103-84782003000400007>. Acesso em: 08 ago. 2013. doi: 10.1590/S0103-84782003000400007.

FORCE, L. et al. New fluorescence parameters for monitoring photosynthesis in plants. Photosynthesis Research, n.78, p.1733, 2003. Disponível em: <http://link.springer.com/article/10. 1023\%2FA\%3A1026012116709>. Acesso em: 08 ago. 2013. doi: 10.1023/A:1026012116709.

GALVAN, J. et al. Anatomia foliar de Lolium multiflorum sensível a resistente ao glyphosate. Planta Daninha, v.30, n.2, p.407-413, 2012.

HISCOX, J.D.; ISRAELSTAM, G.F. A method for the extraction of chlorophyll from leaf tissue without maceration. Canadian Journal \& Botany., v.57, p.1132-1334, 1979. Disponível em: <http://www.nrcresearchpress.com/doi/abs/10.1139/b79-163\#>. Acesso em: 07 maio, 2012.

KASPARY, T.E. et al. Resistência de biótipos de azevém ao herbicida glyphosate no RS. In: JORNADA ACADÊMICA INTEGRADA, 25., 2010, Santa Maria, RS. Anais... Santa Maria: UFSM, 2010. Disponivel em: <http://portal.ufsm.br/jai2010/anais/ trabalhos/trabalho_1041242656.htm>. Acesso em: 21 ago. 2013.

KASPARY, T.E. et al. Características biológicas de biótipos de Lolium multiflorum 1. suscetível e resistentes ao herbicida glyphosate. In: CONGRESSO BRASILEIRO DA CIÊNCIA DAS PLANTAS DANINHAS, 28., 2012, Campo grande, MS. Anais... Disponivel em: <http://www.congressosbcpd.com.br/sistemainscricoes/documentos_ cientificos/pdf/157 _ XXVIIICBCPD $>$. pdf. Acesso em: 28 nov.2013.

LI, R. et al. Effects of salt and alkali stresses on germination, growth, photosynthesis and ion accumulation in alfalfa (Medicago sativa L.). Soil Science \& Plant Nutrition, v.56, p.725-733,
2010. Disponível em: <http://onlinelibrary.wiley.com/doi/10.1111/ j.1747-0765.2010.00506.x/pdf $>$. Acesso em: 08 ago. 2013. doi: 10.1111/j.1747-0765.2010.00506.x.

LICHTENTHALER, H.K. Chlorophylls and carotenoids: pigments of photosynthetic biomembranes. In: PACKER, L.; DOUCE, R. (Eds.). Methods in enzymology. Bad Honnef : Academic, v.148, p.350-382, 1987. Disponível em: <http://dx.doi. org/10.1016/0076-6879(87)48036-1>. Acesso em: 08 ago. 2013. doi: 10.1016/0076-6879(87)48036-1.

MOURA, M.L. et al. Crescimento e desenvolvimento de frutos do tomateiro 'Santa Clara' e do seu mutante natural 'firme'. Ciência e Agrotecnologia, v.28, n.6, p.1284-1290, 2004. Disponível em: <http://www.scielo.br/scielo.php?pid=S141370542004000600009\&script $=$ sci arttext $>$. Acesso em: 08 ago. 2013. doi: 10.1590/S1413-70542004000600009.

NAKAZONO, E.M. et al. Crescimento inicial de Euterpe edulis Mart. em diferentes regimes de luz. Revista Brasileira de Botânica, v.24, n.2, p.173-179, 2001. Disponível em: <http:// www.scielo.br/scielo. php?script=sci_arttext $\&$ pid $=$ S0100-84042001000200007>. Acesso em: 08 ago. 2013. doi: 10.1590/S0100-84042001000200007.

NEVES, O.S.C. et al. Uso do SPAD-502 na avaliação dos teores foliares de clorofila, nitrogênio, enxofre, ferro e manganês do algodoeiro herbáceo. Pesquisa agropecuária brasileira., v.40, p.517521, 2005. Disponível em: $<$ http://www.scielo.br/scielo.php?pid= S0100-204X2005000500014\&script=sci_arttext $>$. Acesso em: 08 ago. 2013. doi: 10.1590/S0100-204X2005000500014.

RIGON, J.P.G. et al. Indirect measurement of photosynthetic pigments in the leaves of Jatropha curcas. Semina: Ciências Agrárias, v.34, n.2, p.669-674, 2013. Disponível em: <http://www. uel.br/revistas/uel/index.php/semagrarias/article/view/10523/ pdf>. Acesso em: 08 ago. 2013. doi: 10.5433/1679-0359.2013v3 $4 \mathrm{n} 2 \mathrm{p} 669$.

RIZZARDI, M.A. et al. Competição por recursos do solo entre ervas daninhas e culturas. Ciência Rural, v.31, n.4, p.707-714, 2001. Disponível em: <http://www.scielo.br/scielo. php?pid=S010384782001000400026\&script=sci_arttext $>$. Acesso em: 08 ago. 2013. doi: $10.1590 /$ S0103-84782001000400026.

SALLA, L. et al. Teores de clorofila em árvores tropicais determinados com SPAD-502. Revista Brasileira de Biociências, v.5, p.59-161, 2007. Disponível em: <http://www.ufrgs.br/seerbio/ ojs/index.php/rbb/article/view/174/163>. Acesso em: 08 ago. 2013.

SCHUELTER, A.R. et al. Avaliação dos níveis de clorofila em folhas de tomateiro da cultivar 'Santa Clara', do mutante 'firme' e do híbrido F1. Acta Scientiarum. Biological Sciences, v.25, n.1, p.183-187, 2003. Disponível em: <http://eduemojs.uem.br/ojs/ index. php/ActaSciBiolSci/article/view/2110/1543>. Acesso em: 08 ago. 2013. doi: DOI:10.4025/ actascibiolsci.v25i1.2110.

SOUSA, J.V. et al. Silicato de potássio via foliar no milho: fotossíntese, crescimento e produtividade. Bioscience Journal, v.26, n.4, p.502-513, 2010. Disponível em: <http://www.seer. ufu. br/index.php/biosciencejournal/article/view/7148/5122>. Acesso em: 08 ago. 2013. 